\title{
Is short stature a problem? The psychological view
}

\author{
Linda D Voss \\ Department of Endocrinology and Metabolism, Peninsula Medical School, Plymouth, UK \\ (Correspondence should be addressed to L D Voss at the EarlyBird Research Centre, Child Health, Level 12, Derriford Hospital, Plymouth PL6 8DH, UK; \\ Email: 1.voss@phnt.swest.nhs.uk)
}

\begin{abstract}
The use of $\mathrm{GH}$ in short normal children remains a controversial issue as physicians and parents alike are under continuing pressure to identify and to treat such children. Before asking who might respond to growth-promoting therapy, we should first ask who needs it. Rational intervention assumes some abnormality, physical or psychological, that can be corrected. Where short stature is the result of GH deficiency, the case for intervention is clear and uncontroversial. Where there is no clear deficiency, treatment can be regarded neither as replacement therapy, nor as corrective, but simply cosmetic. However, there might be a case for therapy if there were clear evidence of an association between short stature and psychosocial dysfunction. The common perception that short stature is an inevitable handicap has been founded on unreliable evidence, largely clinic-based studies, where children experiencing the greatest difficulties are likely to be found. Such reports, unless challenged, can only lead to an increasing demand for treatment, both from and for those who were previously unconcerned. The Wessex Growth Study recruited an unselected cohort of short normal children, not from the clinic, but from the community at large, and has challenged the widely held belief that short stature is an inevitable disadvantage. The progress of these children, followed over some 13 years, has given little cause for concern. Indeed, this study, and others subsequently, has demonstrated the normality of the psychosocial functioning of the short normal child.
\end{abstract}

European Journal of Endocrinology 155 S39-S45

\section{Introduction}

In 2003, the Food and Drug Administration (FDA) signed the seal of approval for growth hormone $(\mathrm{GH})$ to be given to children with idiopathic short stature (ISS), i.e. stature on or below the 1.2 percentile, even where there is no discernible medical problem (1). It was a landmark decision, and not without controversy $(2,3)$. As Allen and Fost remarked, 'the cause of the short stature has ceased to be morally relevant in deciding, who is entitled to treatment' (4). It seems likely that a similar application will be made in the European Union (5). All that is now required is evidence of a disability arising from short stature (SS).

Prior to the advent of biosynthetic GH in 1985, limited supplies of GH were strictly rationed and only those children with classic GH deficiency (GHD) were eligible for treatment. Thereafter, limitless supplies have led to an increasing number of approved indications, such as Turner's syndrome, Prader-Willi's syndrome,

This paper was presented at the 4th Ferring Pharmaceuticals International Paediatric Endocrinology Symposium, Paris (2006). Ferring Pharmaceuticals has supported the publication of these proceedings. chronic renal insufficiency and 'small-for-gestational age' $(2,6)$. A condition known as GH 'insufficiency' was also a target, prompted by the observation that the distribution of GH secretion appears to be continuous, tall children secreting more GH than short (7).The fact that biochemical tests for GHD are unreliable only strengthened the argument and led, inevitably, to this somewhat grey area of 'insufficiency' at the lower end of the continuum.

An apparently poor rate of growth also became a criterion for therapy (8). Short-term growth data, however, largely because of measurement error, cannot reliably distinguish between normal and abnormal growth $(9,10)$. Crucially, there is no correlation between successive annual height velocities, so that height velocity, even over 12 months, neither predicts the future nor reports the past. In the long-term, of course, short children will grow more slowly than tall, but this does not make their rate of growth abnormal. 'Normal' height velocity is conditional on stature (11). Indeed, were all children to grow at a uniform rate, there would be no variation in adult stature.

What has arisen over recent years is, in essence, a situation where short stature has become medicalised, allowing even the short normal child to become a 
potential target for growth-promoting therapy. To begin with, GH was largely given in the context of clinical trials, but the recent FDA ruling will have opened the floodgates. The exact proportions of children currently receiving treatment are unknown, but even before 2003 , one report suggested some $40 \%$ of children on GH appeared not to be GHD (12), and at one time in the US, ISS alone accounted for around one in three of all children on GH (13).

One argument used in support of GH therapy for the short normal child is based on the notion that medicine is about the relief of suffering, the treatment of people, not diseases (14). Why should we offer GH only to the child who is GH deficient and withhold it from another, who is GH replete but equally short, when the goals, such as an improvement in psychosocial functioning, might be the same? (15). Although there may be metabolic benefits of GH therapy in some pathological conditions, in most cases, the rationale behind the treatment is an increase in height velocity in the shortterm and taller adult height. This is based on a widespread belief that SS constitutes a psychosocial disadvantage and that is where the disability lies, but where should we look for the evidence?

\section{Stature and social stereotypes}

Social stereotypes associated with unusual stature at either end of the range of height include the so-called 'gentle giant' at one extreme and the derogatory 'shortman syndrome' or 'Napoleon complex' at the other. The literature suggests that social stereotypes of height may be established at an early age. Even very young children ascribe positive attributes to tall and negative attributes to short silhouettes (16). Experimental studies with young adults in hypothetical social situations have shown 'status' to equate with 'stature', whereby tall men are attributed qualities expected of successful people (17). The results of other studies indicate that those in high-esteem jobs are generally believed to be taller than those in low-status jobs $(18,19)$. A physically imposing presence apparently confers an advantage in modern day politics, at least in the US, where taller presidential candidates have typically won elections (20). In the absence of additional information, first impressions may well be biased by popular stereotypes, but it has been shown that the influence of height is diminished where contextual factors, such as education and other individual characteristics are incorporated. Although there have been some reports linking height and income, they are inconsistent and the relationship is attenuated when controlled for potentially confounding variables, such as level of education, marital status and race $(2,21,22)$.

\section{Short stature in the paediatric clinic}

Most commonly, SS appears as an isolated physical characteristic in an otherwise healthy child, i.e. 'idiopathic SS'. Nevertheless, the belief that such children are disadvantaged by their height is widespread (23-26). In one survey, $56 \%$ of physicians said that height impaired emotional well-being in children below the third percentile (27). There are several likely explanations for this belief.

Until recently, almost all studies designed to assess the psychological adaptation of children with SS were based on clinically referred patients with a whole variety of medical diagnoses. The underlying pathology specific to each condition, one such example would be Turner's syndrome, is likely to hamper normal psychosocial and educational adjustment. Moreover, many of the earlier studies were conducted at a time when GH therapy was strictly rationed, and thus will have included only those most severely affected by their SS.

Problems of social adaptation reported to the paediatrician have included stigmatization, juvenilisation, immaturity and unassertiveness (28). Some have suggested that short children are conditioned to behave in a socially immature manner and that the stereotypical anxious, introverted short child could well be the result of 'experiences associated with the small stature' $(29$, 30 ). The child or adolescent, who is treated according to height age rather than chronological age is likely to withdraw from the peer group, or may prefer to socialise with younger children or even adults. Some short children might perhaps try to overcompensate for SS by being over assertive and belligerent or to seek peer approval as the group mascot or clown (31). Alternatively, it has been suggested that some adults overly protect the short child from his/her peer group (32-34). Parental overprotection has in fact been shown to be a strong predictor of victimization by peers in the general school population (35).

Most reports on short children's school performance have also been based on clinic-referred samples (36). These studies commonly report academic underachievement in spite of average intelligence, but are likely to reflect specific neurocognitive deficits associated with specific syndromes, rather than the psychosocial consequences of SS $(28,37)$. Importantly, it has been shown that within clinic-referred populations the problems of academic achievement are not related to height, nor are they remedied by GH therapy $(37,38)$.

SS is commonly associated with delayed puberty and Gordon et al. were the first to propose that the psychological benefits of accelerating height velocity might outweigh any reduction in final adult height (39). There is no evidence, however, to support this. Although delayed puberty may serve as an additional problem in adolescents with SS, the data are inconclusive (40-44). Most studies seem to confirm few long-term psychological sequelae of early growth delay (45-47). 
Many clinic-based studies have been subject to a variety of methodological flaws, not only mixed diagnostic groups, mixed age groups and small sample sizes, but also they have often lacked an appropriate control or comparison group (48). Volunteer controls are likely to yield an above average group in terms of psychological functioning (49). Details of short stature recruitment into studies sponsored by the pharmaceutical industry are often lacking, making it impossible to assess how representative they are. A recent review of all referrals for SS to the growth clinic over a 12-month period found twice as many boys as girls, even though boys are no more prone to SS (50). This gender bias would seem to reflect a social or cultural difficulty, at least in the US, in accepting short stature in males.

The findings from more recent clinic-based studies, with improved methodology, have questioned many of the established beliefs regarding the psychosocial consequences of SS (51). In 1994, Sandberg reported on 522 consecutive referrals for SS to the paediatric clinic, using both parent and self-report measures. The majority of youths with short stature experienced teasing or juvenilisation, but only minor difficulties of behavioural adaptation were identified (52). A Dutch study reported similar findings for a group of untreated young adults with idiopathic SS. The authors of this study concluded that although three quarters of the participants reported a negative experience attributed to their SS, this had not resulted in a reduced quality of life (QOL) (53). Skuse and colleagues detected no significant differences in terms of peer acceptance, self-perception or social competence between physically healthy clinicreferred short children and their classmates (54). Further analysis of this study revealed that intelligence was a better predictor than height for most aspects of psychosocial adjustment (55).

\section{Short stature in the community}

Most of the children with idiopathic SS' or 'short normal stature' will never appear in the paediatric clinic and it would be a mistake to conclude that the psychosocial or educational experience of those who have been medically evaluated will be typical of those in the general population. On the contrary, they are likely to be those who are (or who are perceived to be) experiencing the greatest educational or behavioural difficulties. So, where to look for the evidence?

The Wessex Growth Study (WGS), a prospective cohort study, was unique in having recruited an unselected population of short, but otherwise healthy children (56). Children with known organic disease were excluded, the age range lay within a tight band, a wide range of socioeconomic classes was represented and the study incorporated case matched controls of average stature. Psychometric testing was largely based on well validated and standardised tests. In this community-based study, few differences were found between the short children and their controls. As others have shown (46), the shorter children, when asked, said they would have preferred to be taller. Although mean IQ between the short and control groups in the WGS was significantly different, height, on its own, explained only $2 \%$ of the variance in IQ, emphasizing the need always to look beyond $P$ values and consider effect size (57).

The WGS was the first study to look at both victims and bullies in the context of physical stature (58). It confirmed that bullying was widespread, regardless of stature, but noted a significant difference between short children and their controls. It is possible that short pupils may simply perceive that they are more bullied, mistaking the normal rough and tumble of the playground for bullying. However, these data could also be explained by the fact that significantly fewer of the controls admitted to being bullied, in spite of the fact that their parents complained that they were. More short pupils did, nevertheless, report a degree of social isolation, perhaps the result, but equally likely the cause of their being bullied. None of the above, however, had a measurable effect over the years on school performance or self-esteem $(48,59)$. As Illich has claimed, one aspect of good health is to be 'successful in coping with reality' (60).

In summary, the WGS has shown no evidence of maladaptation or psychosocial dysfunction, before, during or after puberty, in these youngsters who were, by current standards, very short indeed $(61,62)$. What the study clearly showed was that socioeconomic factors, rather than stature, best predict psychosocial and academic outcome. In one recent study of a large cohort of Swedish conscripts, poorer health, more psychological problems and a lower mean intellectual performance in those with a height more than 2 s.D. below the mean were reported. Crucially, however, no correction was made for social background (63).

Other studies have followed confirming the inherent bias in clinic-based samples. Busschbach et al. compared adults with idiopathic SS, who had presented as children to a paediatric clinic, with equally short adults sampled from the population (64). The former clearly had poorer coping skills, and claimed that the social disadvantages of SS dominated their social interactions. The latter showed no impairment in their QOL. Kranzler et al. directly compared three groups: referred and nonreferred children with SS and case controls of average stature (65). The referred SS group exhibited significantly more behaviour problems than the non-referred SS group, who were indistinguishable from controls. The authors concluded that the discrepancy between earlier and more recent research could be explained by participant selection bias. Finkelstein and colleagues examined the leisure behaviour of three groups of adolescents: those with short stature, delayed puberty and diabetes mellitus. Their activities and experiences were no different and, indeed, were similar to 
non-clinical comparison groups (66). Finally, an original and definitive large-scale community-based study has recently been reported. Using peer informants, Sandberg et al. were able to assess psychosocial adaptation across the range of heights in middle- and high-school students. No statistically significant relationships were found between height and measures of friendship, popularity or most aspects of reputation among peers, despite substantial statistical power. The authors concluded that extremes of stature in the general population, short or tall, have minimal impact on peer perceptions of social behaviour or acceptance among classmates. Even the very shortest children made friends and earned the respect of their peers as well as any other (67).

\section{Does GH make a difference?}

Papers continue to appear in the literature purporting to demonstrate the benefits of growth hormone $(\mathrm{GH})$ therapy. The evidence, however, rarely extends beyond an apparent gain in final height (68). The corollary of the assumption that SS is disadvantageous is that the addition of a few centimetres must help psychosocial functioning. In a recent survey in the US, $32 \%$ of physicians believed that GH makes a difference and that an increase in height will improve the QOL in non-GHD SS (27). Blethen assures that 'other benefits of $\mathrm{GH}$ therapy include improvement in psychosocial functioning' (69), yet there is no rigorously controlled study to show a benefit from so doing.

In one widely quoted study, the benefits of GH could have been explained by regression towards the mean (70). As Sandberg has remarked, changes observed in the treated group were not compared with changes seen over the same period in a sample with similarly elevated baseline scores (71). Theunissen recently looked at QOL and self-esteem in children diagnosed with ISS and found them largely comparable to population norms (72). Moreover, despite an increase in height in those randomly treated, there was no clear improvement in measures of psychosocial adaptation compared with untreated controls. The paediatrician reported an improvement, the parents no change, and the children either no change or a deterioration. In a retrospective study of two groups of adults with ISS, no differences were seen in educational level or QOL between those who had received GH in childhood and those who had not. Unexpectedly, the untreated group was more likely to report having a romantic partner (73).

In the only randomised, double blind, placebo controlled study of the psychosocial effects of GH in ISS, the psychosocial adaptation and self esteem of the GH-treated youngsters were comparable to that of the placebo group at baseline (74). Interestingly, relatively taller children showed more emotional problems at baseline than the very shortest, replicating an earlier finding by this group (52). During the first 2 years of treatment, no significant differences in psychosocial adaptation between the two treatment arms were detectable. At no point did measures of self-esteem differ, but in the fourth year, parents reported significantly more behaviour problems in the placebo-treated group. Nevertheless, no systematic relationship was observed between change in height and change in psychosocial adjustment.

Finally, where there is no GHD, the outcome of GH treatment is generally not very dramatic in terms of centimetres gained and in ISS is largely unpredictable $(68,75,76)$. Nevertheless, it has been claimed that parents, and their children, usually regard the immediate psychological benefits of a short-term increase in growth rate as justifying the treatment, even if the longterm improvement is minimal (77), but there is little evidence to support this notion from the few longitudinal trials to include a psychometric assessment (78-80). In summary, most commentators agree that GH treatment of ISS or short normal stature cannot be justified $(5,81,82)$.

\section{Ethical issues}

The ethical problems associated with attempting to enhance the stature of a short, but otherwise healthy child have been well rehearsed (83). Not least is that by increasing the height of all those below an arbitrary percentile, we inevitably leave a new group below that cut-off. As Freemark has pointed out, this may be the only circumstance in which treatment of one group of children creates illness in another previously healthy group (3). Routine growth screening may be of value if it facilitates the detection of previously undetected pathology, but most short children thus identified will have no obvious pathology (84). Care must be taken to reassure them that they are indeed healthy and normal. Importantly, it had been demonstrated that perceived height is a better predictor of psychosocial adaptation than measured height (85).

Pressure to treat may come from sources that are not in the child's best interests. Whenever investigators are funded to discover new indications for a drug, commercial pressures inevitably come into play (86). Indeed, the cynical view would be that shortness only became a disease when a treatment became available (83). As Gill reminds us, terms such as 'short normal stature', 'normal variant short stature' and 'familial short stature' have been around for a while. ISS, on the other hand, is a relatively recent concoction and implies that these children are suffering from some, as yet, undiagnosed endocrine disorder (5). He notes that the term does not appear in the index of any of the large standard paediatric text books, in the UK or the US.

Demands for treatment may also be motivated, less by concern for the children, than by aspirations of their 
parents. Some, including those with children well within the normal range for height, may seek $\mathrm{GH}$ therapy because they perceive tallness to be desirable and wish to give their own offspring a perceived advantage in life by enhancing what are essentially normal physical characteristics (87). The danger here is that any attempt by parents to modify their child's appearance may signal tacit disapproval and lead them to feel unacceptable as they are (88). Children as well as parents can also overestimate the potential for final height, leading to disappointment and perceived treatment 'failure' $(85,89)$.

A further consideration is the long-term safety of recombinant human $\mathrm{GH}$, which has yet to be established, especially when given in supra-physiological doses effects $(90,91)$. Although few adverse events have been documented to date, the increase in incidence of type-2 diabetes recently reported in children is one concern (92). Young children do not understand the risks and benefits of therapy and cannot give valid, informed consent or even assent (93).

There is a serious economic consideration as well, with estimates from $€ 50000$ to $€ 75000$ for a course of treatment to more than $\$ 35000 /$ inch $(\$ 14000 / \mathrm{cm})$ $(5,76)$. There is a clear argument for not spending limited resources on expensive, so-called 'cosmetic endocrinology', when there may be cheaper (albeit largely untried) options $(5,75,94)$. Moreover, if treatment becomes an option available only to those who can afford to pay, social injustice inevitably follows by selectively allocating morbidity to poor children (93).

Central to the ethical argument is the notion that most of the short children are indeed normal and, as such, do not require growth-promoting drugs. However, the term 'normal' is no longer simply descriptive, showing us what is, in the sense of usual or typical. It has become prescriptive, telling us how things ought to be (83). As Illich has warned, 'Society has become a clinic, and all citizens have become patients whose blood pressure is constantly being watched and regulated to fall within normal limits' (60).

\section{Conclusion}

The continuing widespread use of GH risks perpetuating a climate of opinion where SS is unacceptable, both to parents and society, and is likely to lead to a spiralling demand for what is increasingly becoming a lifestyle drug. There remains a wealth of literature, in both the medical and the popular press, warning physicians and parents alike of the difficulties that the short individual might expect to encounter and a real danger of these publications themselves creating anxiety in those who were previously unconcerned.

There is no compelling evidence to show an association between short stature and cognitive and psychosocial maladaptation or dysfunction. Any problems, academic, behavioural or psychological, that a short child might meet in life are not necessarily attributable to short stature. There is an urgent need to redress the balance with this more positive message. Parents and children alike should be reassured by these findings.

\section{References}

1 Food and Drug Administration: FDA approves Humatrope for short stature. FDA Talk paper. July 25, 2003. Available at: www. fda.gov/bbs/topics/ANSWERS/2003/ANS01242.html. Accessed March 12, 2006.

2 Sandberg DE \& Colsman M. Growth hormone treatment of short stature: status of the quality of life rationale. Hormone Research $200563275-283$

3 Freemark M. Editorial: growth hormone treatment of 'idiopathic short stature': not so fast. Journal of Clinical Endocrinology and Metabolism 200489 3138-3139.

4 Allen DB \& Fost N. hGH for short stature: ethical issues raised by expanded access. Journal of Pediatrics 2004144 648-652.

5 Gill DG. 'Anything you can do, I can do bigger': the ethics and equity of growth hormone for small normal children. Archives of Disease in Childhood 200691 270-272.

6 Bridges NA. New indications for growth hormone. Archives of Disease in Childhood Practice Edition 200590 ep7-ep10. doi: 10.1136/ adc.2004.061382.

7 Hindmarsh P, Smith P, Brook C \& Matthews D. The relationship between height velocity and 24 growth hormone secretion in children. Clinical Endocrinology 198727 581-591.

8 Buchlis JG, Irizarry L, Crotzer BC, Shine BJ, Allen L \& MacGillivray MH. Comparison of final heights of growth hormone-treated vs. untreated children with idiopathic short stature. Journal of Clinical Endocrinology and Metabolism $1998 \mathbf{8 3}$ $1075-1079$

9 Voss LD, Bailey BJR, Cumming K, Wilkin TJ \& Betts PR. The reliability of growth measurement. Archives of Disease in Childhood 1990651340.

10 Voss LD, Wilkin TJ, Bailey BJR \& Betts PR. The reliability of height and height velocity in the assessment of growth. Archives of Disease in Childhood 199166 833-837.

11 Voss L \& Mulligan J. Normal growth in the short normal prepubertal child. Journal of Medical Screening 19985 127-130.

12 KIGS International Board/Pharmacia Corporation. Pharmacia International Growth Database, Report No. 18. Biannual Report, Stockholm, March 2001.

13 Vance ML \& Mauras N. Growth hormone therapy in adults and children. New England Journal of Medicine 1999341 1206-1216.

14 Churchill LR. Bias, opportunity and justice in growth hormone therapy. In Growth, Stature and Adaptation, pp 195-202. Eds B Stabler \& LE Underwood, Chapel Hill: University of North Carolina, 1994.

15 Neely EK \& Rosenfeld RG. Use and abuse of human growth hormone. Annual Review of Medicine 1994 45 407-420.

16 Clopper R. Height and children's stereotypes. In Growth, Stature and Adaptation, pp 7-18. Eds B Stabler \& LE Underwood, Chapel Hill: University of North Carolina, 1994.

17 Martel LF \& Biller HB. Stature and Stigma: The Biopsychosocial Development of Short Males. Lexington, MA: DC Heath, 1987.

18 Lechelt EC. Occupational affiliation and ratings of physical height and personal esteem. Psychological Reports 197536 943-946.

19 Wilson PR. Perceptual distortion of height as a function of ascribed status. Journal of Social Psychology 1968 74 97-102.

20 Gillis JS. Too Tall, Too Small. Champaign, IL: Institute for Personality and Ability Testing, 1982.

21 Ekwo E, Gosselink C, Roisen N \& Brazdziunas D. The effect of height on family income. American Journal of Human Biology 19913 181-188. 
22 Judge TA \& Cable DM. The effect of physical height on workplace success and income: preliminary test of a theoretical model. Journal of Applied Psychology 20048 428-441.

23 Stabler B \& Gilbert MC. Psychological effects of growth delay. In Growth Abnormalities, pp 255-274. Eds R Hintz \& R Rosenfeld, New York: Churchill Livingstone, 1987.

24 Lee PDK \& Rosenfeld RG. Psychosocial correlates of short stature and delayed puberty. Pediatric Clinics of North America 198734 851-863.

25 Underwood LE. The social cost of being short: societal perceptions and biases. Acta Paediatrica Scandinavia. 1991377 (Suppl) 3-8.

26 Stabler B, Siegel PT, Clopper RR, Stoppani CE, Compton PG \& Underwood LE. Behavior change after growth hormone treatment of children with short stature. Journal of Pediatrics 1998133 366-373.

27 Cuttler L, Silvers JB, Singh J, Marrero U, Finkelstein B, Tannin G \& Neuhauser D. Short stature and growth hormone therapy. A national study of physician recommended patterns. Journal of the American Medical Association 1996276 531-537.

28 Sandberg DE. Short stature: intellectual and behavioral aspects. In Pediatric Endocrinology, 3rd edn, pp 149-162. Ed. F Lifshitz, New York: Marcel Dekker, 1996.

29 Lerner RM \& Gellert E. Body build identification, preference and aversion in children. Developmental Psychology 19691 456-462.

30 Steinhausen HC \& Stahnke N. Negative impact of growth hormone deficiency on psychological functioning in dwarfed children and adolescents. European Journal of Pediatrics 1977126 263-270.

31 Meyer-Bahlburg HFL. Short stature: psychological issues. In Pediatric Endocrinology. A Clinical Guide, 2nd edn, pp 173-196. Ed. F Lifshitz, New York: Marcel Dekker, 1990.

32 Kusalic M, Fortin C \& Gauthier Y. Psychodynamic aspects of dwarfism. Response to growth hormone treatment. Canadian Psychiatric Association Journal 197217 29-34.

33 Rotnem D, Genel M, Hintz RL \& Cohen DJ. Personality development in children with growth hormone deficiency. Journal of the American Academy of Child Psychiatry $1977 \mathbf{1 6}$ 412-426.

34 Holmes CS, Hayford JT \& Thompson RG. Parents and teachers differing views of short children's behaviour. Child: Care, Health and Development 19828 327-336.

35 Olweus D. Bully/victim problems among schoolchildren: basic facts and effects of a school based intervention program. In The Development and Treatment of Childhood Aggression, pp 411-448. Eds DJ Pepler \& KH Rubin, Hillsdale, NJ: Lawrence Erlbaum Associates, 1991.

36 Voss LD \& Mulligan J. The short 'normal' child in school: selfesteem, behaviour and attainment before puberty (The Wessex Growth Study). In Growth, Stature and Adaptation, pp 47-64. Eds B Stabler \& LE Underwood, Chapel Hill: University of North Carolina, 1994.

37 Lagrou K, Xhrouet-Heinrichs D, Heinrichs C, Craen M, Chanoine JP, Malvaux P \& Bourguignon JP. Age-related perception of stature, acceptance of therapy, and psychosocial functioning in human growth hormone-treated girls with Turner's syndrome. Journal of Clinical Endocrinology and Metabolism $1998 \mathbf{8 3}$ 1494-1501.

38 Sandberg DE, MacGillivray MH, Clopper RR, Fung C, LeRoux L \& Alliger DE. Quality of life (QOL) among formerly treated childonset growth hormone-deficient (GHD) adults: a comparison with unaffected siblings. Journal of Clinical Endocrinology and Metabolism 199883 1134-1142.

39 Gordon M, Crouthamel C, Post EM \& Richman RA. Psychosocial aspects of constitutional short stature: social competence, behavior problems, self-esteem and family functioning. Journal of Pediatrics 1982101 477-480.

40 Drash PW. Psychologic counselling in dwarfism. In Endocrine and Genetic Diseases of Childhood, pp 1014-1022. Ed. LI Gardner, Philadelphia, PA: WB Saunders, 1969.
41 Zimet GD, Cutler M, Litvene M, Dahms W, Owens R \& Cuttler L. Psychological adjustment of children evaluated for short stature: a preliminary report. Journal of Developmental and Behavioral Pediatrics $199516264-270$.

42 Apter A, Galatzer A, Beth-Halachmi N \& Laron Z. Self-image in adolescents with delayed puberty and growth retardation. Journal of Youth and Adolescence 198110 501-505.

43 Lewis VG, Money J \& Bobrow NA. Idiopathic pubertal delay beyond age fifteen: psychologic study of 12 boys. Adolescence 197712 1-11.

44 Holmes CS, Karlsson JA \& Thompson RB. Social and school competencies in children with short stature. Longitudinal patterns. Journal of Developmental and Behavioral Pediatrics 1985 6 263-267.

45 Zimet G, Cutler M \& Owens R. Psychosocial functioning of adults who were short as children. In Growth, Stature and Adaptation, pp 73-82. Eds B Stabler \& LE Underwood, Chapel Hill: Universtiy of North Carolina Press, 1994.

46 Crowne EC, Shalet SM, Wallace WHB, Eminson DM \& Price DA. Final height in boys with untreated constitutional delay in growth and puberty. Archives of Disease in Childhood 199065 1109-1112.

47 Crowne EC, Shalet SM, Wallace WHB, Eminson DM \& Price DA. Final height in girls with untreated constitutional delay of growth and puberty. European Journal of Pediatrics 1991150 708-712.

48 Voss LD \& Mulligan J. The short 'normal' child in school: selfesteem, behaviour and attainment before puberty (The Wessex Growth Study). In Growth, Stature and Adaptation, pp 47-64. EdsB Stabler \& LE Underwood, Chapel Hill: University of North Carolina Press, 1994.

49 Rosenthal R \& Rosnow RL. The Volunteer Subject. New York: Wiley, 1975.

50 Grimberg A, Kutikov JK \& Cucchiara AJ. Sex differences in patients referred for evaluation of poor growth. Journal of Pediatrics 2005 $146212-216$.

51 Sandberg DE \& Voss LD. The psychosocial consequences of short stature: a review of the evidence. Best Practice and Research, Clinical Endocrinology and Metabolism 200216 449-463.

52 Sandberg DE, Brook AE \& Campos SP. Short stature: a psychosocial burden requiring growth hormone therapy? Pediatrics 199494 832-840.

53 Rekers-Mombarg LTM, Busschbach JJV, Massa GG, Dicke J \& Wit JM. Quality of life of young adults with idiopathic short stature: effect of growth hormone treatment. Acta Paediatrica 1998 87 865-870.

54 Skuse D, Gilmour J, Tian CS \& Hindmarsh P. Psychosocial assessment of children with short stature: a preliminary report. Acta Paediatrica Scandinavia $1994 \mathbf{4 0 6}$ (Suppl) 11-16.

55 Gilmour J \& Skuse D. Short stature-the role of intelligence in psychosocial adjustment. Archives of Disease in Childhood 199675 25-31.

56 Voss LD, Walker JM, Lunt H, Wilkin T \& Betts P. The Wessex Growth Study B first report. Acta Paediatrica Scandinavia 1989349 (Suppl) 65-72.

57 Sandberg DE. Should short children who are not deficient in growth hormone be treated? Western Journal of Medicine 2000172 186-189.

58 Voss LD \& Mulligan J. Bullying in school B are short children at risk? British Medical Journal $2000320612-613$.

59 Downie AB, Mulligan J, Stratford RJ, Betts PR \& Voss LD. Are short normal children at a disadvantage? British Medical Journal 1997 314 97-100.

60 Illich I. Limits to Medicine. UK: Penguin Books, 1996.

61 Voss LD. Short but normal. Archives of Disease in Childhood 1999 81 370-371.

62 Ulph F, Betts P, Mulligan J \& Stratford RJ. Personality functioning: the influence of stature. Archives of Disease in Childhood 200489 17-21. 
63 Tuvemo T, Jonsson B \& Persson I. Intellectual and physical performance and morbidity in relation to height in a cohort of 18-year-old Swedish conscripts. Hormone Research 199952 $186-191$.

64 Busschbach JJV, Rikken B, Grobbee DE \& De Charro FT. Quality of life in short adults. Hormone Research $199849032-38$.

65 Kranzler JH, Rosenbloom AL, Proctor B, Diamond FB Jr \& Watson M. Is short stature a handicap? A comparison of the psychosocial functioning of referred and non-referred children with normal short stature and children with normal stature Journal of Pediatrics 2000136 96-102.

66 Finkelstein JW, Caldwell LL \& Demers E. Leisure behavior of youth with short stature, delayed puberty and diabetes mellitus. Journal of Pediatric Endocrinology and Metabolism 200316 869-875.

67 Sandberg DE, Bukowski WM, Fung CM \& Noll RB. Height and social adjustment: are extremes a cause for concern and action? Pediatrics $2004114744-750$.

68 Hintz RL, Attie KM, Baptista J \& Roche A. Effect of growth hormone treatment on adult height of children with idiopathic short stature. Genentech Collaborative Group. New England Journal of Medicine $1999340502-507$.

69 Blethen SL \& MacGillivray MH. A risk-benefit assessment of growth hormone use in children. Drug Safety 199717 303-316.

70 Stabler B, Siegel PT, Clopper RR, Stoppiani CE, Compton PG \& Underwood LE. Behaviour change after growth hormone treatment of children with short stature. Journal of Pediatrics $1998133366-373$.

71 Sandberg DE, Kranzler J, Bukowski WM \& Rosenbloom AL. Psychosocial aspects of short stature and growth hormone therapy. Journal of Pediatrics 1999135 133-134.

72 Theunissen NC, Kamp GA, Koopman HM, Zwinderman KA, Vogels T \& Wit JM. Quality of life and self-esteem in children treated for idiopathic short stature. Journal of Pediatrics $20021 \mathbf{1 4 0}$ 507-515.

73 Rekers-Mombarg LT, Busschbach JJ, Massa GG, Dicke J \& Wit JM. Quality of life of young adults with idiopathic short stature: effect of growth hormone treatment. Dutch Growth Hormone Working Group. Acta Paediatrica 199887 865-870.

74 Ross JL, Sandberg DE, Rose SR, Leschek EW, Baron J, Chipman JJ, Cassorla FG, Quigley CA, Crowe BJ, Roberts K \& Cutler GB Jr. Psychological adaptation in children with idiopathic short stature treated with growth hormone or placebo. Journal of Clinical Endocrinology and Metabolism 200489 4873-4878.

75 Guyda HJ. Growth hormone therapy for non-growth hormonedeficient children with short stature. Current Opinion in Pediatrics $199810416-421$.

76 Finkelstein BS, Imperiale TF, Speroff T, Marrero U, Radcliffe DJ \& Cuttler L. Effect of growth hormone therapy on height in children with idiopathic short stature: a meta-analysis. Archives of Pediatrics and Adolescent Medicine 2002156 230-240.

77 Thomsett M. Who should be treated with human growth hormone? Medical Journal of Australia 1993158 802-804.

78 Scarth LG, Gardiner HM, Valentine S \& McGhee AM. By taking thought: psychological studies of treated short normal children. In Growth, Stature and Adaptation, pp 107-121. Eds B Stabler \& LE Underwood, Chapel Hill: University of North Carolina, 1994.
79 Downie AB, Mulligan J, McCaughey E, Stratford RJ, Betts PR \& Voss LD. Psychological response to growth hormone treatment in short normal children. Archives of Disease in Childhood 199675 32-35.

80 Boulton TJC, Dunn SM, Quigley CA, Taylor JJ \& Thompson L. Perceptions of self and short stature: effects of two years of GH treatment. Acta Paediatrica Scandinavia 1991377 (Suppl) 20-27.

81 Brook CG. Growth hormone: panacea or punishment for short stature? British Medical Journal 1997315 692-693.

82 Wygold T. Psychosocial adaptation to short stature - an indication for growth hormone therapy? Hormone Research 200258 (Suppl 3) 20-23.

83 Voss LD. Growth hormone therapy for the short normal child: who needs it and who wants it? Journal of Pediatrics 2000136 103-110.

84 Voss LD, Mulligan J, Betts PR \& Wilkin TJ. Poor growth in school entrants as an index of organic disease. British Medical Journal 1992305 1400-1402.

85 Hunt L, Hazen RA \& Sandberg DE. Perceived versus measured height: which is the stronger predictor of psychosocial functioning? Hormone Research 200053 129-138.

86 Lantos JD. Ethics and growth hormone: where have we been and where are we going?. In Growth, Stature and Adaptation, pp 213-219. Eds B Stabler \& LE Underwood, Chapel Hill: University of North Carolina, 1994.

87 Neely EK \& Rosenfeld RG. Use and abuse of human growth hormone. Annual Review of Medicine $1994 \mathbf{4 5} 407-420$.

88 Diekema DS. Is maximizing height good parenting? Endocrinologist 200111 (Suppl 1) 67-71.

89 Rotnem D, Cohen D, Hintz R \& Genel M. Psychological sequelae of relative 'treatment failure' for children receiving $\mathrm{GH}$ replacement. Journal of the American Academy of Child Psychiatry 197918 505-520.

90 Wilton P. Adverse events during GH treatment: 10 years' experience in KIGS, a pharmacoepidemiological survey. In Growth Hormone Therapy in KIGS-10 Years' Experience, pp 349-364. Eds MB Ranke \& P Wilton, Mannheim: Barth, 1999 (Edition J\&J).

91 Clayton PE \& Cowell CT. Safety issues in children and adolescents during growth hormone therapy - a review. Growth Hormone and IGF Research $200010306-317$.

92 Cutfield WS, Wilton P, Bennmarker H, Albertsson-Wikland K, Chatelain P, Ranke MB \& Price DA. Incidence of diabetes mellitus and impaired glucose tolerance in children and adolescents receiving growth-hormone treatment. Lancet 2000355 610-613.

93 Lantos J, Siegler M \& Cuttler L. Ethical issues in growth hormone therapy. Journal of the American Medical Association 1989261 1020-1024.

94 Eminson M, Powell RP \& Hollis S. Cognitive behaviour interventions with short statured boys: a pilot study. In Growth, Stature and Adaptation, pp 135-150. Eds B Stabler \& LE Underwood, Chapel Hill: University of North Carolina, 1994.

Received 28 April 2006

Accepted 20 July 2006 